Anatol Jakobson, Tatyana Kirillova

Irkutsk State Railway University

Konstantin Lidin, Natalia Batsun, Elena Gafarova

Irkutsk State Technical University

\title{
Some problems of transition to post-industrial development in the Siberian region
}

Irkutsk Oblast of the Russian Federation is usually regarded as an industrial region. Its economy is oriented predominantly at extracting industries (coal, gas, iron ore, gold, salt, mica, timber cutting, hydropower) and first stages of processing (including petrochemicals and aluminium using imported raw materials). The principle proprietors (earlier sectoral ministries, now trans-national corporations) have their headquarters very far from Siberia and their interests are rather alien to the region. In fact, such a picture makes even the given definition ("industrial region") somehow doubtful and too optimistic. However, it can be said that we deal here with an early stage of industrialization, far from post-industrial development.

Still, all this does not mean that such functions as science, education, or culture do not exist here. They do exist but are not used as "locomotives" of regional economy.

In the last several years, the authors of the report have taken part in investigations and discussions on strategic planning of regional development in Irkutsk Oblast for the first half of the $21^{\text {st }}$ century. Three scenarios were analyzed in details.

One of them, the conservative one, is based on the existing trends of development. It means that further development of the region will be resource oriented (power, aluminum, timber, etc.) as it has been for decades and even for centuries. This scenario is the least efficient and promising but it requires minimum efforts from the regional administration.

The second scenario is called "New Industrialization". It includes re-structuring the regional industry through extending natural resources processing. That is, producing aluminum alloys and products instead of raw aluminum, or plywood and furniture instead of timber. This variant is the most balanced but at the same time rather risky from the environmental point of view.

The third scenario is based on the idea of transition to post-industrial economics. It means the leading role of services in the development of the regional economy. In this variant, the role of the intellectual activity grows immensely. While modern industrial technologies in today's world come usually from remote global centres, in the sphere of services it is impossible. For example, the development of the most promising tourist sector requires taking into account the unique specificity of the local system of the geographic position, climate, 
history, ethnic culture and image. Without this, there is no chance to achieve competitiveness in tourist attractiveness.

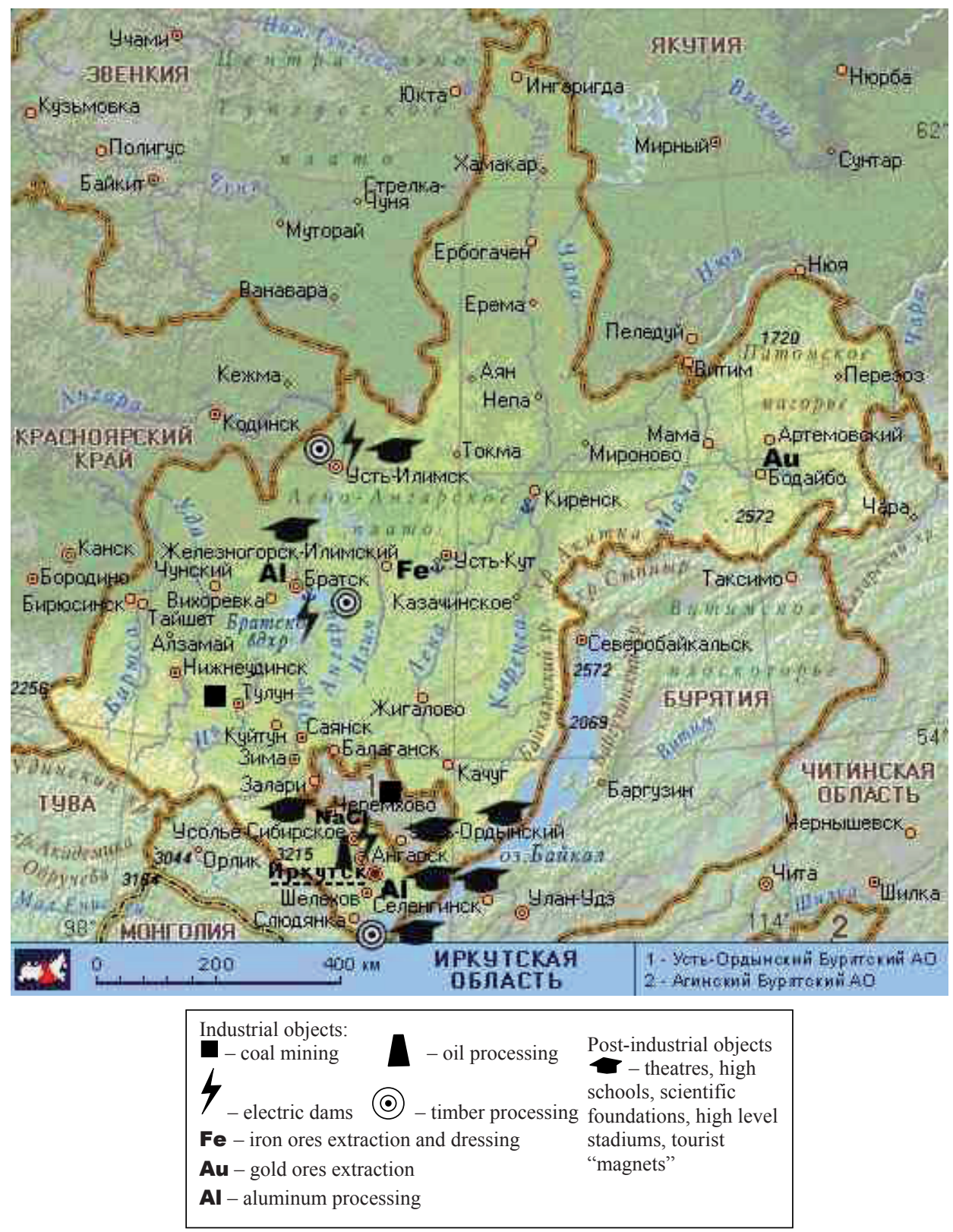

Ill. 1. The economy of Irkutsk Oblast

The advantages of this scenario seem obvious. It leads the region to the up-to-date ways of development. It stimulates the development of the intellectual potential of the local popu- 
lation. It is connected with preservation of the unique natural system of lake Baikal. But in reality this way would demand an enormously deep restructuring of thinking, of mentality, of the whole system of values, which doesn't seem very probable.

An interesting intermediate scenario presumes a specific combination of "New Industrial" and post-industrial ways. In this scenario, the Oblast is divided into two zones easily distinguishable at the map of the Oblast (Fig. 1), that is, the industrial North and South having some real chances for post-industrial development, as almost all centres of science, higher education and services are now densely concentrated in Irkutsk and around it.

But in reality, today's tendencies of regional development are more likely to follow the conservative scenario. The sectors mentioned above in reality do not get any support from the regional and local authorities. There exist no backing up programmes for higher schools or scientific institutions. The business in the sphere of hotels, restaurants and other service industries does not receive any governmental attention either. Even the department of tourism in the Oblast Government was dismissed this year.

At the same time, the heads of traditional major industrial enterprises have a strong influence in the system of regional power and use it for getting cheap credits and land for new constructions for their businesses.

This demonstrates that mental inertia is in fact stronger than economic and social factors.

One of the problems transition from industrial economy to post-industrial society deals with is the problem of transition at the level of an industrial city, or perhaps a city that used to be industrial. While the country is looking for and finding new ways of development, connected with other cities and towns, such a city seems to be doomed for stagnation.

But such cities can find their specific way inside the processes of transition, and this way can be tightly connected with the former industrial development. There are even two such ways. One is the development of education and science, and the design of activity in the branch the city has been famous for.

Let us take Cheremkhovo, traditionally a coal-mining centre, about $200 \mathrm{~km}$ to the West from Irkutsk. Having been the second city in the Oblast, it began to stagnate since 1960s quite a typical process for such settlements in the whole world.

One of the ideas of converting the local economy in post-industrial direction could be development of professional training, which seems rather promising, taking into account the problem which is becoming acute in the whole country - that is the lack of skilled industrial, transportation and construction workers.

Another example is Baikalsk, a pulp-and-paper works town at the very shore of the famous lake, the symbol of environment pollution (Fig. 2). Since its foundation in early 1960s, a public struggle against its existence has been taking place. The principle obstacle preventing the destruction of the plant has been the fact that it is practically the only enterprise giving jobs to the local population. There are a lot of ideas as to converting the town economic structure, including development of tourism or uniting two or three Federation entities located near the lake (including Irkutsk Oblast) into one with Baikalsk as the capital.

All these ideas are rather interesting but maybe the most promising is the idea of developing here a hi-tech industry specialized in production of environment-control devices. Such a specialization, instead of pollution and rather primitive pulp and paper, will make the town a new symbol, a symbol of greening, and in this status it will have opportunities to attract other desired functions. 


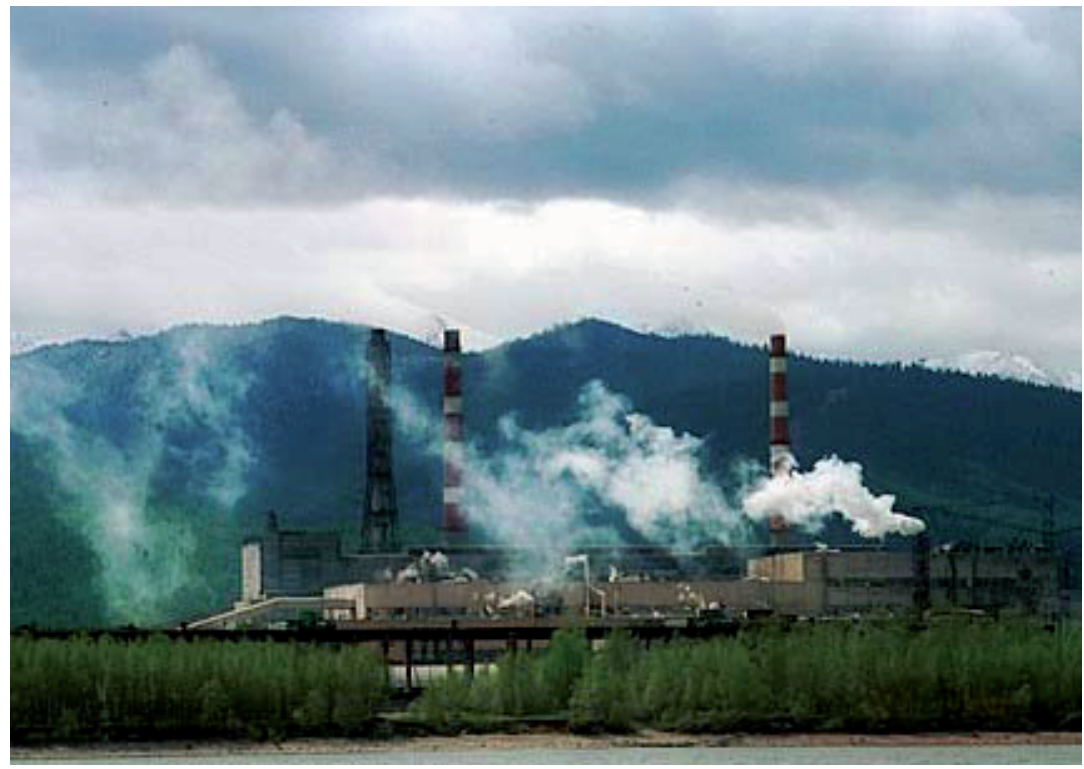

Ill. 2. Baikalsk pulp and paper works - on the very bank of the lake, before the ridge of picturesque mountains

But there is another way, that is the development of tourism. Unfortunately, all attempts to discuss this option are usually blocked by one argument: there are no tourist magnets in the region but Baikal. In fact, this argument seems completely wrong.

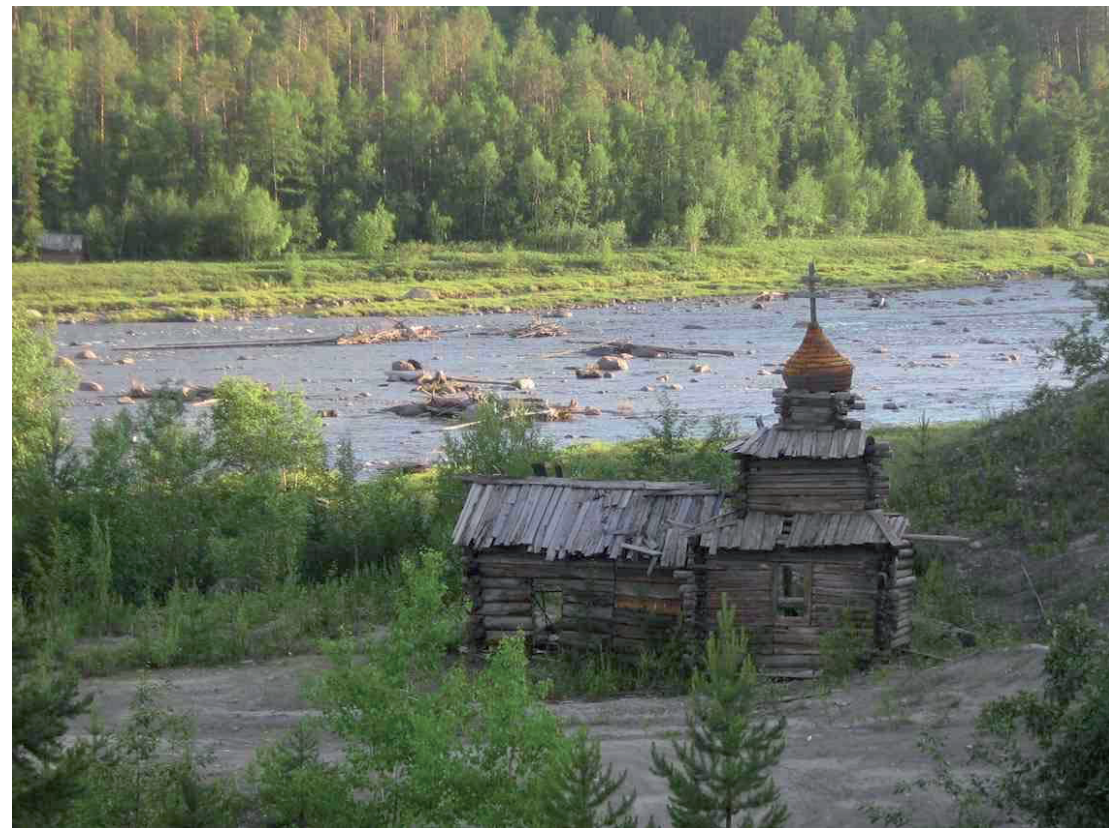

Ill. 3. "Little old church" near Baikal 
In fact, it was constructed about twenty years ago for movie making. But now it has become an attractive tourist object

Let us take concrete examples. More than 10 years ago, one of the authors was lucky to visit one of the biggest cities in Poland - Lódź. His Polish friends had tried to talk him out of this idea: there are such interesting places in the country as Warsaw, Kraków, Wrocław, Gdańsk, Lublin, etc, with their Gothic, Renaissance and Baroque palaces, cathedrals and castles. What can be interesting in Lódź that emerged only in the $19^{\text {th }}$ century, with its bourgeois, tasteless architecture?

But he did come to this non-touristic city, and never has he regretted. For he saw a city of its own epoch. Yes, in that time people constructed buildings of that style. Tasteless? No, according to the taste of the Poznańskis and other rich families of the age. This is another style, this is another taste. Of course, Wawel and Sukiennice are much more beautiful. But they will never tell a guest about the $19^{\text {th }}$ century in Poland, while the streets of Lódź will. It is a very deep idea, important for tourism: any epoch, good or bad, is worth memory.

A conclusion: the industrial image of the city is not a characteristic that should be overcome in the process of transition and be converted into something quite different or even opposite. It is a background on which the new image can be and should be constructed.

Such a conclusion seems valid for a lot of cities and towns of ex-Soviet states.

However, this idea meets some unexpected problems that can be demonstrated on the example of Sevastopol (Ukraine), again using personal experience. This city is at the stage of transition (although its former and today image has been a bit different; it has been a naval military base), state and local governments try to convert it into a tourist city. But these attempts meet strong lack of traditional service mentality among the citizens.

A bit differently looks the problem of tourist services development in a sub-region that is really pre-industrial. It is a very specific administrative unit of Irkutsk Oblast, the Olkhon district, which is situated on the very bank of Baikal Lake and on the major island of the same name. The population is rather scarce and is characterized by an original ethnic structure, half Russian, half Buryat. Before the market reforms, the regional economy could be called backward, as it consisted of several state agricultural enterprises with negative indices of efficiency, as well as one fishery and fish-processing factory.

The reforms have brought a spontaneous development of tourism, as the area is rich in attractive landscapes (Fig. 4), places of ethnic and historical interest, hunting and fishery potential, etc.

Certain hopes were connected with the development of agriculture and agricultural industry. But in fact, the development has followed two separate ways. The numerous private peasant farms, which have emerged in place of the state enterprises, are still economically inefficient, while the Fish Works has been bought by a company registered in Moscow and its activity is no more included into the regional economy.

Our investigations have shown that the most effective way of development of the area shall be further development of tourism services, including hotels, restaurants, transportation, guide services etc. This sector should and can be oriented towards the local labour force. These people are in fact undereducated and unacquainted with the contemporary Western level of service, but it must not be considered as a deficiency, because for European tourists (including those from European Russia) it looks like an element of the local exotics, especially when it is usually compensated by sincerity and hearty attitude. This is a principal difference between this place and Sevastopol, where tourists expect a high level of services. 


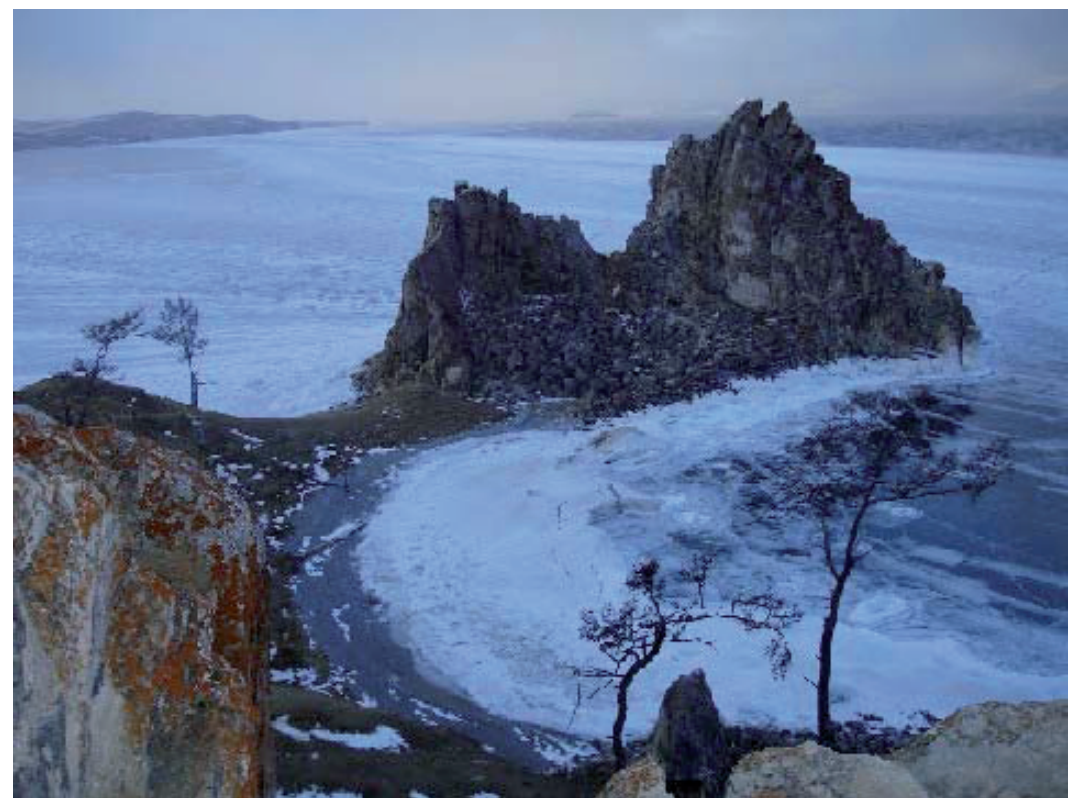

Ill 4. Cape Shaman (Olkhon Island)

As for agriculture, it seems that it can survive only in the complex with tourism service, as a means of providing the tourists with environmentally pure products, especially meat and fish, inside the same or neighbouring peasant households.

As a method of uniting these sectors into one spatial complex, the well-known concept of industrial clusters can be used. In this case, it should mean co-operation of small businesses belonging to local peasants under an active organizing role of the local and regional administrative authorities, leaning on the recommendations of academic specialists.

Speaking about the development of Baikal tourism, we should bear in mind that lake Baikal is highly popular in Russia, in other ex-Soviet states and in the world. This name is usually associated with wild nature and pure water. This very name can serve as a brand attracting people to the region. But at the same time, it can also serve to mark food (and maybe some other products) that satisfy certain standards.

Is it really so? Do the consumers want to buy environmentally pure products? Are they ready to pay and overpay for this purity?

In Russia, the State Standard relating to informing consumers on food products restricts using such terms as "environmentally pure", demanding that such terms be based on some documents proving it. But in practice, many producers ignore this demand, motivated by high interest of consumers in such products.

The data of a poll organized in St. Petersburg in 2005 show that 85 per cent are ready to buy the products that are highly safe from the environmental point of view, even if their price is 10 per cent higher, while 45 per cent would accept a 20 per cent price growth, and 28 per cent would agree with a 30 per cent increase. Such indices are high enough even in comparison with most developed and socially conscious countries.

To answer the same questions, we have arranged a poll in Irkutsk. Two groups were investigated: students and people above 35 years of age. 
Answering the question about associations connected with the word "Baikal", both groups were unanimous expressing pride and admiration, as well as feeling that Baikal symbolizes natural beauty, environmental purity and health. Students, being more educated, sometimes used the term "brand" - that was their own initiative, without any influence of the investigators.

For 80 per cent of our respondents, the word "Baikal" is connected with feeling of trust in the goods made of local products that are expected to be environmentally pure.

The next question was: "Which statement about a product could make you overpay for it?" The most popular were the following ones: "Does not contain preservatives and other synthetic components"; "Made from environmentally pure products"; "Produced using Baikal water".

But only 1 per cent (and only among students) chose the variants "Produced with resource saving (or environment protecting) technologies". This demonstrates that in fact people take care not so much about environment but mostly about their own health. But nevertheless, the importance of the Baikal brand is approved.

It is broadly used as a brand, but often without proving one's rights to such usage (Fig. 5). Sometimes it is even applied to some goods produced far from Siberia and having nothing to do with the famous lake.
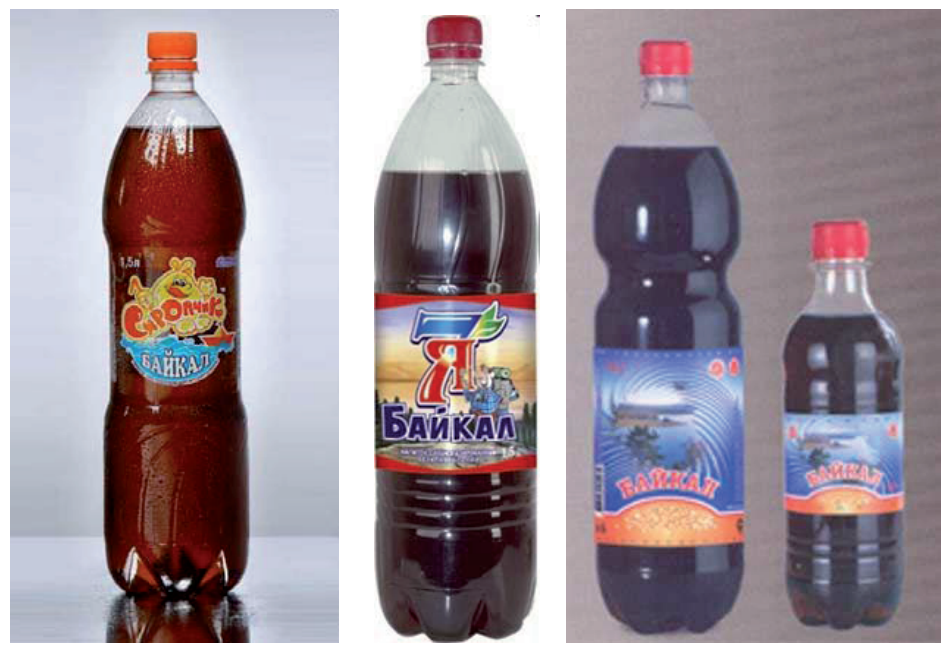

Ill. 5. Drinks named "Baikal" (similar to Pepsi-Cola) are produced in different regions of Russia very remote from real Baikal (from the left to the right - Nizhniy Novgorod, Omsk, St.-Petersburg).

Their quality is also very remote from that of the purest Baikal water

The possibility for the regional and local authorities to manage the usage of the Baikal brand would permit it to play an effective role in regional marketing and in greening of the Siberian business.

Still, it is necessary to remember that the idea that any product of the Baikal region is always environmentally pure oversimplifies the real situation. It becomes clear owing to the analysis of one special problem.

The basin of Upper Angara is one of many regions of the world that suffer from iodine deficit in water, soil and air. This brings numerous endemic diseases, and hence - social and 
economic losses. These losses have been calculated as the sum of direct and indirect medical costs and lost benefits. The latter means underproduction in the region because of diseases, and, in the long term, lowering of the intellectual potential.

In the conditions of state-owned planned economy the problem had been solved rather effectively through production (obligatory for the enterprises) of iodine-enriched salt and massive population-informing policy stimulating its consumption. Today, market enterprises are not interested in such production, as it is connected with extra expenditures. At the same time, today's technologies permit to produce not only iodine-enriched salt, but as well bread, eggs, milk, sugar, macaroni, etc.

Our marketing investigation has shown that iodine-enriched food is a product with high demand elasticity. Lowering the product price to the level of non-enriched analogues would bring a 38 per cent increase in demand. Such a situation is a result of many years of absence of any informational activity in this field.

Again, this example demonstrates that the mentality of the mass of consumers is often free from logical succession. It contains contradictions and fragments that are not connected with each other. Environment protecting technologies seem to have nothing to do with environmental purity, while iodine-enriched products are not associated with health. To tell the truth, the producers, as well as officials, do little to promote this association (Fig. 6).

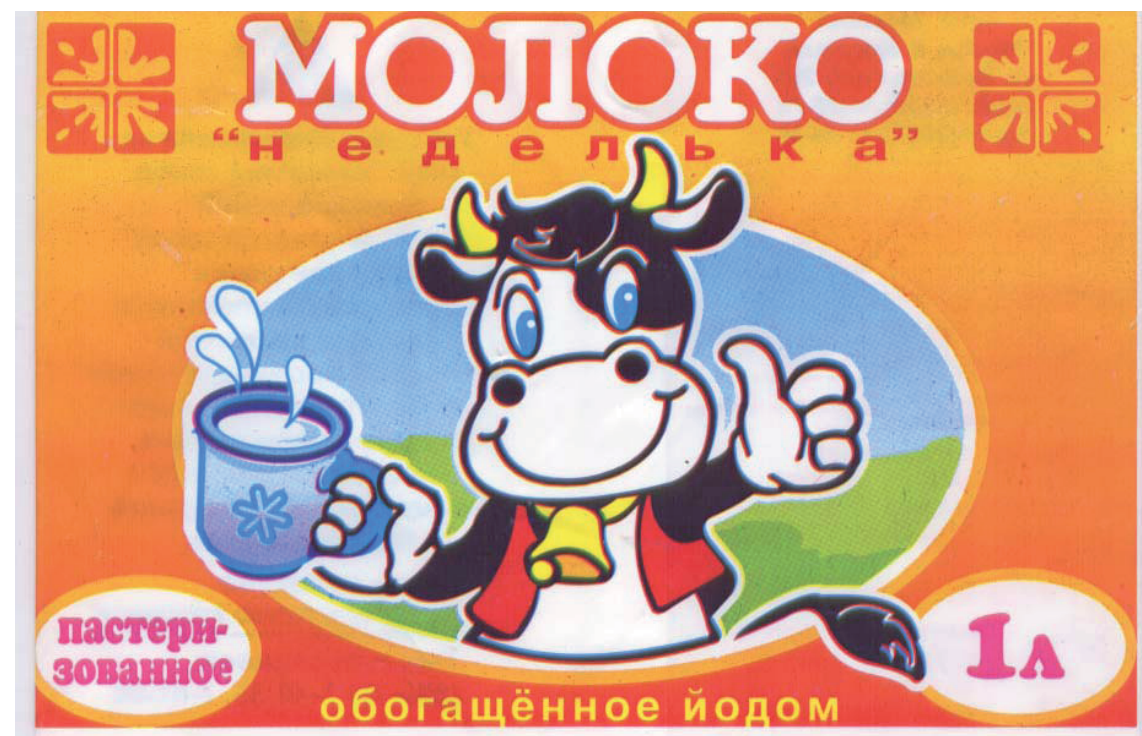

Ill. 6. The label of one of the iodine enriched products. The words "iodine enriched" are hardly noticeable and are not commented from the point of view of health protection

At another level, the task of developing tourist services in the region is not recognized by the business and the regional government as connected with brand policy.

These mental effects should be considered as thresholds on the way to the post-industrial development. 
prof. dr Anatol Jakobson

Irkutsk State Railway University, Russia

e-mail: yakobson_ay@irgups.ru

doc. Konstantin Lidin

Irkutsk State Technical University, Russia

e-mail: lidin@adexi.ru

doc. Natalia Batsun

Irkutsk State Technical University, Russia

e-mail: nbatsun@mail.ru

doc. Elena Gafarova

Irkutsk State Technical University, Russia

e-mail: persik17@mail.ru

doc. Tatyana Kirillova

Irkutsk State Railway University, Russia

e-mail: tatyana@irgups.ru 